\title{
Effects of Shoulder Abduction in Opposite Directions on EMG Activity in the Abdominal Muscles during Single Leg Raising in the Supine Position on the Foam Roller in Healthy Subjects
}

\author{
Sung-Joon Yun, Moon-Hwan Kim \\ Department of Physical Therapy, The Graduate School, Yonsei University, Wonju, Korea
}

Purpose: The purpose of this study was to examine the electromyographic (EMG) activity of the abdominal muscles and to compare the activity ratios of the bilateral rectus abdominis (RA) to oblique abdominal muscles during shoulder abduction in opposite directions with single leg raising (SLR) performed in the supine position on a foam roller.

Methods: Fifteen healthy subjects were recruited to the study. Each subject lay on the foam roller and performed left single leg raising with right or left shoulder $90^{\circ}$ abduction (Abd); performed in a random order. Surface EMG recordings of selected abdominal muscles (i.e., the RA, external oblique abdominis [EO], internal oblique abdominis [IO], and transverse abdominis [TrA]) were normalized to maximum voluntary isometric contraction. EO/RA and IO and TrA/RA ratios were determined with surface EMG. Data were analyzed by Independent t-test. The statistical significance level was $p<0.05$.

Results: The results were as follows: (1) the right RA, left EO, and right 10 and TrA muscle activities increased significantly at the left SLR with left Abd compared to the left SLR with right Abd $(p<0.05)$; and (2) the ratio of right EO/RA activity increased significantly at the left SLR with right Abd compared to left Abd $(p<0.05)$.

Conclusion: These findings suggest that left SLR with left Abd on a foam roller is an appropriate exercise for activation of specific oblique abdominal muscles.

Keywords: Foam roller, Oblique abdominis, Shoulder abduction

\section{서 론}

허리통증의 원인은 주로 몸통과 팔다리가 움직이는 동안 척추를 중 립 자세로 유지하는 데 기여하는 몸통 근육들의 근력 약화나 부적절 한 동원방식 등으로 설명된다.' 반복적인 허리 회전과 팔다리의 움직 임은 몸통의 회전을 초래하고, 이로 인해 척추의 회전이 발생하여 척 추 구조물에 추가적인 미세손상을 유발한다. ${ }^{2}$ 그렇기 때문에 일상생 활에서 팔을 뻗어 물건을 잡거나 자동차에 타고 내리는 등의 동작을 수행하기 위해서 빈번하게 허리를 회전시키거나 반복적으로 가쪽 굽 힘을 하는 사람들에게 허리통증이 많이 발생하게 된다. ${ }^{3}$

Sahrmann ${ }^{4}$ 은 허리에서 발생되는 많은 문제의 원인으로 골반과 척 추(L5-S1) 사이의 안정성을 제공하는 배근육들의 근력 약화와 협응 력 저하를 보고하였다. 허리 통증을 경험하는 환자에게 통증의 감소

Received Jul 23, 2015 Revised Aug 17, 2015

Accepted Aug 20, 2015

Corresponding author Moon-Hwan Kim

E-mail agafimu@hanmail.net
를 목적으로 적용되는 허리 안정화 운동은 심부근들의 독립적인 수 축 훈련과 근력 강화, 그리고 특정 동작을 수행하는 동안 허리를 중립 상태로 유지하는 데 필요한 심부근과 큰 힘이 필요한 동작에서 사용 되는 표재근들의 동시수축 훈련이 포함되어야 한다고 보고되었다.5,6 허리 안정화 운동에 대한 최근 연구들에서는 운동의 지지면 변화나 팔다리의 움직임을 이용하여 몸통의 안정성에 기여하는 특정 근육 의 수축과 심부근과 표면근의 동시 수축을 유도하기 위한 목적으로 진행되고 있다.

불안정한 지지면은 허리 안정성에 기여하는 근육의 강화와 동시 수축 능력 향상을 위해 허리 안정화 운동에서 보편적으로 사용되는 방법이다. ${ }^{6-10}$ 이전 연구들에 따르면 불안정한 바닥면에서 허리 안정 화 운동을 시행하는 것이 배곧은근과 배바깥빗근, 배속빗근과 가로 배근의 활성도를 높이는 데 더 효과적인 것으로 나타났다.7-10 특히 불 
안정한 바닥면에서 시행되는 운동은 배곧은근의 수축을 많이 유도 한다고 보고되지만, ${ }^{79}$ Richardson 등1의 연구에 의하면 배곧은근의 높은 근활성은 허리 안정화 운동에 적합하지 않다고 하였다. 하지만, 불안정한 바닥면에서 허리 안정화 운동을 실시하면, 운동하는 동안 팔다리의 움직임에 의해 균형동요(perturbation)가 발생하게 되고, 이 러한 동요로부터 몸통의 안정성을 유지하기 위해 몸통 근육들이 동 시에 수축하게 된다.12,13 또한, 실제의 일상생활 속에서 이루어지는 대 부분의 움직임들은 정적인 상태보다 동적인 상태에서 이루어지며, 팔과 다리의 움직임도 복합적으로 발생된다. 때문에 다리와 팔의 움 직임이 동반되었을 때 몸통 근육들의 근활성도의 변화와 환자에게 적용할 때 환자의 능력에 맞는 배근육들의 특정 수축 패턴 훈련에 대 한 연구가 필요할 것으로 생각된다.

따라서 본 연구에서는 불안정한 바닥면에서 한쪽 다리를 든 상태 에서 어깨관절 벌림 방향의 변화가 배근육들의 근활성도와 배곧은 근과 빗근들의 근활성비에 미치는 영향을 알아보고자 한다.

\section{연구방법}

\section{1. 연구대상}

본 연구는 남성 15 명의 자발적인 참여에 의해 시행되었고, 대상자들 의 일반적인 특성은 평균연령 $22.7 \pm 2.2$ 세, 신장 $174.7 \pm 4.6 \mathrm{~cm}$, 체중 $70.1 \pm 5.9 \mathrm{~kg}$ 이었다. 모든 참가자의 우세손은 오른쪽이었다. 연구에 참 여한 대상자들은 허리 통증의 경험이 없는 사람, 다리의 염좌나 골절 에 의해 수술 경험이 없는 사람, 폼롤러(Thera-Band Pro Foam Rollers $6 \times 36$ inch, Sammons Preston Rolyan, Bolingbrook, IL, USA)에 누워 한 쪽 다리를 든 상태로 교각자세를 5 초 이상 버틸 수 있는 사람으로 선 정하였다. 만약 정형외과적(양 다리의 길이 차이, 척추 측만증, 척추 후만증 등), 신경학적 손상이 있거나 연구자의 지시를 이해하지 못하 는 사람은 제외하였다.

\section{2. 실험도구}

\section{1) 표면 근전도(Surface EMG)}

폼롤러에 한쪽 다리를 들고 바로 누운 자세에서 어깨관절 벌림 방향 의 변화에 따른 근활성도의 변화를 측정하기 위하여 표면 근전도 기 기인 NORAXON Telemyo 2400T (Telemyo 2400T, NORAXON Inc., Scottsdale, AZ, USA) 시스템을 사용하였다.

근전도 자료수집은 양쪽 배곧은근, 배바깥빗근, 배속빗근과 가로배 근으로부터 들어오는 신호를 이용하였다. 본 연구에서 근전도 전극의 부착 부위로 배곧은근은 배꼽의 외측 $2 \mathrm{~cm}$ 지점, 배바깥빗근은 배꼽 외측과 위 앞엉덩이뼈가시 위를 만나는 지점, 배속빗근과 가로배근은 위 앞엉덩이뼈가시와 두덩결합 사이의 중간 지점을 선택하였다.1415 표본수집률(sampling rate)은 $1,000 \mathrm{~Hz}$ 였고, 잡음을 제거하기 위해 대역통과필터(bandpass filter) 20-450 Hz로 하였고, 전기기기의 잡음 을 최소화하기 위해 대역필터(notch filter) $60 \mathrm{~Hz}$ 를 사용하였다. 수집 된 근전도 신호는 제곱 평균 제곱근법(root mean squar, RMS)으로 처 리하여 분석하였다.

근전도 신호를 어깨관절의 벌림 방향에 따라 비교하기 위하여 최 대 등척성 수축(maximum voluntary isometric contraction, MVIC)을 사용하여 근전도 신호를 표준화하였다. 최대 등척성 수축은 각 측정 자세에서 5 초간 유지하도록 하였고, 각 근육별로 3 회씩 반복 측정하 였다. ${ }^{9}$

몸통에 회전력을 주기 위해 왼쪽 다리를 든 상태에서 오른손 또는 왼손에 $1 \mathrm{~kg}$ 의 무게를 적용하였고, 측정 자세를 5 초간 유지하게 하였 다. 수집된 5 초간의 자료에서 초기 1 초, 마지막 1 초는 제외하고, 중간 구간 3 초간의 자료를 분석하였다. 각 자세별 측정에서 근피로를 막기 위해 1 분간의 휴식 시간을 제공하였다. 근육의 활동을 표준화하기 위해 \%MVIC를 이용하였다.

\section{3. 실험절차}

대상자에게 폼롤러 위에서 바로 누운 자세를 유지하게 한 후 엉덩관 절과 무릎관절의 굴곡 각도를 측정하기 위해 기포경사계(Baseline bubble inclinometer, model 12-1056, Fabrication Enterprises; White Plains, New York)를 사용하였다. 지면을 지지하고 있는 오른쪽 다리 는 엉덩관절 $45^{\circ}$, 무릎관절 $70^{\circ}$ 굴곡된 상태를 유지하게 하고, 왼쪽 다 리는 무릎을 편 상태로 발목에 목표점을 이용하여 과도한 엉덩관절 의 굴곡을 막았다(Figure 1A). 폼롤러 위에서 바로 누운 자세를 유지 할 때 양 다리가 벌어지는 것을 막기 위해 고무줄과 측정자의 지시를 이용해 되먹임(feedback) 기법을 이용하였다. 대상자에게 실험과정을 설명한 후, 폼롤러와 실험과정의 적응을 위해 30 분(10분 적응훈 련-10분 휴식시간-10분 적응훈련) 동안 적응훈련을 하였다. 대상자 는 적응훈련이 끝난 후 근피로를 막기 위해 15 분 동안 휴식시간을 가 진 후 실험을 위한 자료 수집을 실시하였다. 실험은 폼롤러 위에 한쪽 다리를 들고 바로 누운 자세에서 무작위로 왼팔(Figure 1B) 또는 오른 팔(Figure $1 \mathrm{C}$ )을 선정한 후 어깨관절을 $90^{\circ}$ 벌림한 상태로 $1 \mathrm{~kg}$ 덤벨을 들게 하고, 그 자세를 5 초간 등척성 수축을 유지하게 한 후 표면근전 도 자료 수집을 하였다. 이 과정은 3 회 반복되었고, 측정 간 1 분간의 휴식을 가지게 하였다. 측정자는 대상자가 폼롤러에 바로 누울 수 있 게 위치를 조정해주었고, 어깨관절 벌림 방향의 변화를 주게 될 때는 3 분간의 휴식시간을 주어 근피로를 최소화하였다. 근전도 전극을 부 착하기 위해 전극 부위를 면도기로 털을 제거하고 의료용 알코올로 닦아내고, 표면 전극을 부착하였다. 

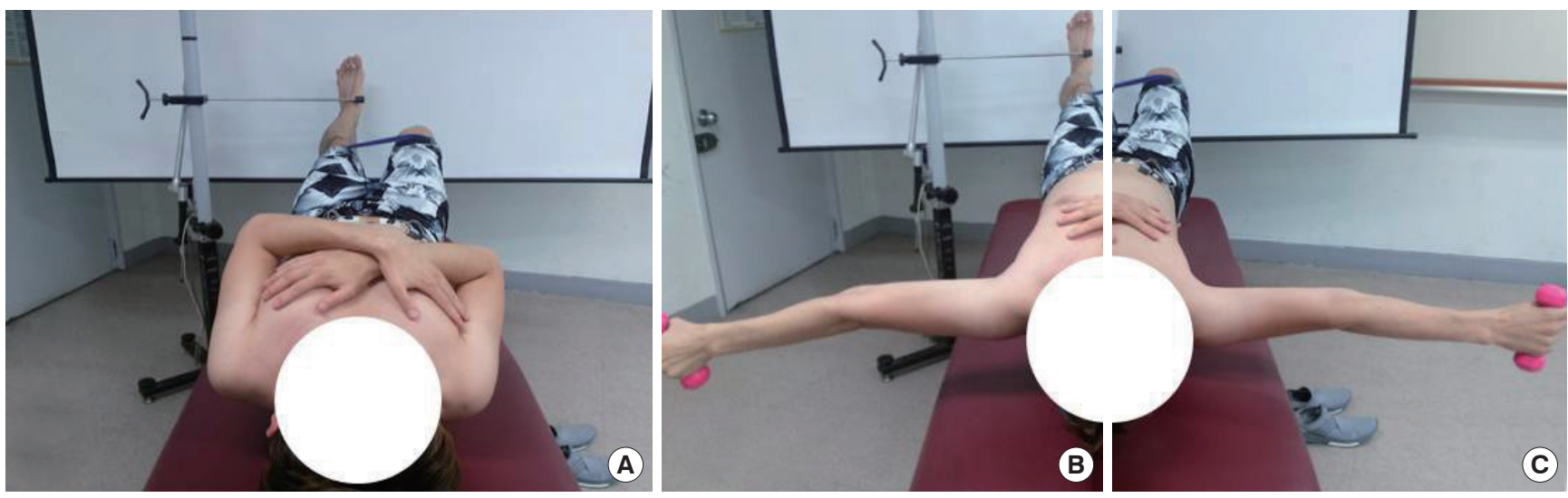

Figure 1. (A) Left single leg raising, (B) Left single leg raising with left shoulder $90^{\circ}$ abduction, and (C) Left single leg raising with right shoulder $90^{\circ}$ abduction.

Table 1. Comparisons of EMG activities of each abdominal muscle

$(\mathrm{N}=15)$

\begin{tabular}{lclcc}
\hline Muscle & $\begin{array}{c}\text { Left SLR } \\
\text { with right Abd }\end{array}$ & $\begin{array}{c}\text { Left SLR } \\
\text { with left Abd }\end{array}$ & $\mathrm{t}$ & $\mathrm{p}$ \\
\hline Right RA & $6.85 \pm 3.38$ & $15.66 \pm 7.82$ & -4.01 & $<0.001^{*}$ \\
Left RA & $11.82 \pm 5.89$ & $17.47 \pm 9.82$ & -1.91 & 0.066 \\
Right EO & $14.15 \pm 7.16$ & $18.23 \pm 9.54$ & -1.33 & 0.196 \\
Left EO & $14.77 \pm 6.98$ & $33.17 \pm 15.74$ & -4.14 & $<0.001^{*}$ \\
Right IO \& TrA & $14.95 \pm 12.62$ & $29.34 \pm 13.45$ & -3.02 & $0.005^{*}$ \\
Left IO \&TrA & $18.39 \pm 8.02$ & $19.75 \pm 8.45$ & -0.449 & 0.657 \\
\hline
\end{tabular}

Values are expressed as mean \pm standard deviation (SD).

SLR, single leg raising; RA, rectus abdominis; EO, external oblique abdominis; IO, internal oblique abdominis; TrA, transversus abdominis; Abd, shoulder $90^{\circ}$ abduction.

${ }^{*} p<0.05$

\section{4. 분석방법}

불안정한 바닥면 위에서 왼쪽 다리를 들고 바로 누운 자세에서 어깨 관절 벌림 방향의 변화에 따른 복부근육 근활성도와 배곧은근의 근 활성도를 이용한 양쪽 빗근들의 근활성비의 차이를 검증하기 위해 독립 표본 t-검정(independent t-test)을 실시하였다. 모든 자료 분석은 통계 프로그램 SPSS ver. 21.0 프로그램(SPSS Inc., Chicago, IL, USA)을 이용하였고, 통계적 유의성 수준은 0.05 로 하였다.

\section{결 과}

폼롤러 위에서 시행된 두 자세에서 왼쪽 다리를 든 상태에서 왼쪽 어 깨관절 벌림이 오른쪽 어깨관절 벌림에 비해 오른쪽 배곧은근, 왼쪽 배바깥빗근과 오른쪽 배속빗근과 가로배근의 근활성도에서 통계학 적으로 유의한 차이가 있었다 $(\mathrm{p}<0.05)$ (Table 1).

양쪽 배곧은근의 근활성도를 이용하여 두 자세에 따른 양쪽 빗근 들의 근활성비를 비교하였을 때 왼쪽 다리를 든 상태에서 오른쪽 어 깨관절 벌림이 왼쪽 어깨관절 벌림에 비해 오른쪽 배바깥빗근의 근
Table 2. Comparisons of muscle acitivty ratios of oblique abdominis to rectus abdominis muscle activity

$(\mathrm{N}=15)$

\begin{tabular}{lcccc}
\hline Ratio (\%) & $\begin{array}{c}\text { Left SLR } \\
\text { with right Abd }\end{array}$ & $\begin{array}{c}\text { Left SLR } \\
\text { with left Abd }\end{array}$ & $\mathrm{t}$ & $\mathrm{p}$ \\
\hline Right EO/RA & $2.29 \pm 1.33$ & $1.20 \pm 0.47$ & 3.00 & $0.006^{*}$ \\
Left EO/RA & $1.38 \pm 0.62$ & $2.58 \pm 2.49$ & -1.81 & 0.080 \\
Right IO \& TrA/RA & $2.77 \pm 2.71$ & $2.57 \pm 2.16$ & 0.23 & 0.823 \\
Left IO \&TrA/RA & $1.89 \pm 1.11$ & $1.75 \pm 1.94$ & 0.24 & 0.810 \\
\hline
\end{tabular}

Values are expressed as mean \pm standard deviation (SD).

SLR, single leg raising; RA, rectus abdominis; EO, external oblique abdominis; IO, internal oblique abdominals; Tara, transversus abdominis; Abd, shoulder $90^{\circ}$ abduction.

${ }^{*} p<0.05$

활성비가 통계학적으로 유의한 차이를 보였다 $(\mathrm{p}<0.05)$ (Table 2).

\section{고 찰}

본 연구에서는 폼롤러 위에서 한쪽 다리를 든 상태에서 어깨관절 벌 림 방향의 변화가 배근육들의 근활성도와 배곧은근과 빗근들의 근 활성비에 미치는 영향을 확인하였으며, 왼쪽 다리를 든 상태에서 왼 쪽 어깨관절 벌림이 오른쪽 어깨관절 벌림에 비해 오른쪽 배곧은근, 왼쪽 배바깥빗근과 오른쪽 배속빗근과 가로배근의 근활성도가 유의 하게 증가하였고, 왼쪽 다리를 든 상태에서 오른쪽 어깨관절 벌림이 왼쪽 어깨관절 벌림에 비해 배곧은근과 비교한 오른쪽 배바깥빗근 의 근활성비가 유의하게 증가하였다.

폼롤러는 둥근 모양을 띄기 때문에 불안정한 바닥면에서 시상면 에서 한쪽 다리를 들고, 이마면에서 어깨관절의 벌림을 유지했을 경 우 지지면(base of support)이 줄어들어 몸통에 큰 회전력이 발생되게 되기 때문에 몸통 안정화를 위해 배근육들이 동시 수축(co-contraction)을 하게 된다. ${ }^{8}$ 배근육들 중에서 배바깥빗근과 배속빗근은 몸통 의 신전과 회전을 조절할 수 있고, 가로배근은 상지의 움직임에 대해 
몸통의 안정성을 유지할 수 있다. ${ }^{4}$ Stevens 등 ${ }^{2}$ 은 네발기기 자세에서 한 쪽 다리를 들었을 때 반대측 배속빗근은 내적 균형을 유지하고, 몸통 에 발생하는 회전력에 대해 골반과 척추의 중립자세를 유지하기 위해 활성화되고, 동측 배바깥빗근 근활성도의 증가도 이와 관련 있다고 하였다. 폼롤러 위에 한쪽 다리를 들고 바로 누운 자세를 취했을 때 동측 배바깥근의 근활성도가 증가되었다. 본 연구에서도 폼롤러 위 에서 왼쪽 다리를 들고 바로 누운 자세를 취하는 동안 왼쪽 어깨관절 벌림을 하였을 때, 다리를 들어올린 방향인 왼쪽 배바깥빗근의 근활 성도 증가를 관찰할 수 있었으며, 이는 이전 연구 결과와 일치한다.29

팔에 적용된 $1 \mathrm{~kg}$ 의 아령은 어깨관절 벌림 각도에 따라 배와 어깨 관절 주변 근육의 근활성도 변화를 초래하였다. Aruin과 Latash ${ }^{16}$ 는 몸통 안정화에 기여하는 배근육들은 팔과 다리의 자세나 적용된 저 항의 위치에 따른 근활성도 변화를 보인다고 보고하였다. Behm 등ㄱ 은 몸통 안정화에 기여하는 배근육을 활성화시키기 위해서는 한쪽 팔에 저항을 적용하면 몸통의 균형에 동요가 발생하게 되고, 외부 저 항에 의해 발생되는 몸통의 균형 동요에 대해 몸통 안정화를 유지하 기 위해 반대측 몸통 근육의 수축과 동원이 발생된다고 보고했다. 다 른 연구에서는 한쪽 엉덩관절이 굴곡 상태를 유지할 때 반대측 가로 배근은 내적 모멘트와 몸통에 발생한 회전력에 대해 골반과 척추의 중립 자세를 유지하기 위해 활성화되고, 이런 활동은 동측 배바깥빗 근의 활성과도 관련있다고 하였다. ${ }^{17}$ 또한, Hodges과 Richardson ${ }^{18}$ 는 가로배근은 팔다리의 움직임 방향에 영향을 받지 않고 수축력을 유 지한다고 보고하였다. 하지만, 본 연구에서는 왼쪽 다리를 든 상태에 서 동측 어깨관절 벌림이 오른쪽 배속빗근과 가로배근, 왼쪽 배바깥 빗근의 증가된 근활성도 관찰할 수 있었다. 이것은 한쪽 다리를 든 상 태에서 동측 어깨관절 벌림으로 증가된 몸통의 균형 동요를 상쇄시 키기 위해 특정 배빗근들의 활성이 증가된 것으로 생각된다.

Marshall과 Murphy ${ }^{10}$ 는 공에 등을 기대고 한쪽 다리를 든 교각운 동을 하는 동안 팔을 움직였을 때 배곧은근의 높은 근활성도를 보고 하였는데, 이는 불안정한 바닥면에서 다리를 들어올리기 위해 증가 된 엉덩관절 굴곡 토크와 몸통에 발생한 회전력에 대해 배곧은근이 대응력으로 작용하였기 때문이다. 하지만 이전 연구에 의하면 배곧 은근은 몸통의 기능적인 움직임이나 안정성에 기여하지 못한다고 하 였고, ${ }^{17}$ Richardson 등1ㅡ는 몸통 안정화 운동을 수행할 때 배곧은근이 다른 허리골반 근육의 근활성에 비해 최소화 되어야 한다고 보고했 다. 본 연구에서는 다리를 들어올린 반대측 배바깥빗근 어깨관절 벌 림 자세에서 배곧은근의 근활성도를 이용하여 양쪽 배바깥빗근과 배속빗근과 가로배근의 근활성 비를 확인하였을 때, 오른쪽 배바깥 빗근에서 통계적으로 유의한 차이를 보였다 $(\mathrm{p}<0.05)$.

본 연구의 제한점은 첫째, 건강한 남성만을 대상으로 연구를 진행 하여 허리 통증이 있는 사람이나 여성에게 이 운동을 적용 시 나타
나는 배근육들의 근활성도 변화를 알아볼 수 없었다. 둘째, 어깨관절 벌림에 관여하는 어깨띠 주변 근육들의 근활성도 변화를 확인하지 않아 오른쪽 배바깥빗근의 높은 근활성도를 정확하게 설명할 수 없 었다. 셋째, 한쪽 다리를 든 상태로 어깨관절 벌림 자세를 유지하기 위 해서는 복부근육의 동시 수축이 유발되고 이로 인해 몸통 관절 간 내압이 상승하게 되어 허리통증 유발의 가능성이 있다. 넷째, 연구에 참여한 대상자의 수가 적어서 결과를 일반화하기 어렵다. 따라서 향 후 연구에서는 허리 통증 환자를 대상으로 팔다리의 움직임에 의해 몸통에 발생하는 회전력을 조절할 수 있는 몸통 안정화 운동이 배근 육과 어깨띠 주변 근활성도 변화가 허리 통증 완화와 근지구력 향상 에 어떠한 영향을 미치는지 알아보는 연구가 필요할 것이다.

본 연구는 불안정한 바닥면에서 다리를 들고 누운 상태에서 서로 다른 방향으로의 팔벌림이 배근육에 미치는 효과를 알아보고자 하 였다. 건강한 남성 대상자를 연구한 결과 불안정한 바닥면에서 좌우 측으로 팔벌림에 의해 몸통에 발생되는 회전력을 조절할 수 있는 배 근육의 선택적 동원 방법을 확인하였다. 폼롤러 위에 누워 왼쪽 다리 를 든 상태에서 왼쪽 어깨관절 벌림 자세가 빗근의 활성화에 효율적 이며, 비대칭적인 빗근의 근활성도를 보이는 허리통증 환자의 상태에 맞게 적용 가능한 허리안정화 운동 방법이라고 사료된다.

\section{REFERENCES}

1. Richardson C, Hodges PW, Hides J. Therapeutic exercise for lumbopelvic stabilization: A motor control approach for the treatment and prevention of low back pain. 2nd ed. London, Churchill Livingstone. 2004: 141-8.

2. Stevens VK, Vleeming A, Bouche KG et al. Electromyographic activity of trunk and hip muscles during stabilization exercises in four-point kneeling in healthy volunteers. Eur Spine J. 2007;16(5):711-8.

3. Van Dillen LR, Sahrmann SA, Norton BJ et al. Reliability of physical examination items used for classification of patients with low back pain. Phys Ther. 1998;78(9):979-88.

4. Sahrmann S. Diagnosis and treatment of movement impairment syndromes. St Louis, Mosby, 2001:69-73.

5. O'Sullivan PB. Lumbar segmental 'instability': Clinical presentation and specific stabilizing exercise management. Man Ther. 2000;5(1):2-12.

6. Kim BK, Lee MH, Kim GC. Comparison of abdominal muscle activity during exercises using a sling and Swiss-ball. J Kor Phys Ther. 2013; 25(3):149-54.

7. Behm DG, Leonard AM, Young WB et al. Trunk muscle electromyographic activity with unstable and unilateral exercises. J Strength Cond Res. 2005;19(1):193-201.

8. Imai A, Kaneoka K, Okubo Y et al. Trunk muscle activity during lumbar stabilization exercises on both a stable and unstable surface. J Orthop Sports Phys Ther. 2010;40(6):369375.

9. Kim SJ, Kwon OY, Yi CH et al. Comparison of abdominal muscle activity during a single-legged hold in the hook-lying position on the floor 
and on a round foam roll. J Athl Train. 2011;46(4):403-8.

10. Marshall PW, Murphy BA. Core stability exercises on and off a Swiss ball. Arch Phys Med Rehabil. 2005;86(2):242-9.

11. Richardson C, Jull G, Toppenberg R et al. Comerford M. Techniques for active lumbar stabilisation for spinal protection: A pilot study. Aust J Physiother. 1992;38(2):105-12.

12. Ng JK, Parnianpour M, Richardson CA et al. Functional roles of abdominal and back muscles during isometric axial rotation of the trunk. J Orthop Res. 2001;19(3):463-71.

13. Jung KS, Chung YJ. Effects of the support surface condition on muscle activity of trunk muscles during weight shifting exercise. J Kor Phys Ther. 2012;24(5):300-5.

14. Cram JR, Kasman GS, Holtz J. Introduction to surface electromyogra- phy. Gaithersburg, Aspen Publishers Inc, 1998:50-5.

15. Escamilla RF, Lewis C, Bell D et al. Core muscle activation during swiss ball and traditional abdominal exercises. J Orthop Sports Phys Ther. 2010;40(5):265-76.

16. Aruin AS, Latash ML. Directional specificity of postural muscles in feedforward postural reactions during fast voluntary arm movements. Exp Brain Res. 1995;103(2):323-32.

17. Callaghan JP, Gunning JL, McGill SM. The relationship between lumbar spine load and muscle activity during extensor exercises. Phys Ther. 1998; 78(1):8-18.

18. Hodges PW, Richardson CA. Feedforward contraction of transversus abdominis is not influenced by the direction of arm movement. Exp brain Res. 1997;114(2):362-70. 